\title{
LETTER
}

\section{Respiratory support withdrawal in intensive care units: international differences stressed and straightened!}

\author{
Jelle L Epker*, Yorick J de Groot and Erwin J Kompanje \\ See related research by Fumis and Deheinzelin, http://ccforum.com/content/14/6/R235
}

\begin{abstract}
We read with great interest the article by Fumis and Deheinzelin [1] in a previous issue of Critical Care. We are convinced that the subject - the withdrawal of respiratory support in intensive care units (ICUs) - is of interest to the ICU community but think that some of the conclusions are somewhat disputable.

First, we agree with the authors that family involvement in the withdrawal process is important; however, this does not necessarily imply that relatives should join in the withdrawal decision-making. This point was already demonstrated by Azoulay and colleagues [2], who showed that direct participation in the withdrawal decision of family members is directly associated with feelings of guilt and the development of post-traumatic stress reactions (PTSRs).
\end{abstract}

\section{Authors' response}

Renata RL Fumis and Daniel Deheinzelin

We thank Epker and colleagues for their comments. The points they make rely upon the fact that end-of-life treatment involves ethical dilemmas. Moreover, under identical clinical circumstances, different physicians may adopt different approaches. As such, there are significant differences in the rates of withdrawing and withholding treatments, the use of advanced directives, the designation of surrogates, and the involvement of families in end-of-life decision-making [5]. In our study, we found that discussions of withdrawing and withholding of life support should be more frequent, and so we are pleased

\footnotetext{
*Correspondence: j.epker@erasmusmc.nl

Department of Intensive Care Medicine, Erasmus Medical Centre, PO Box 2040, 3000 CA Rotterdam, The Netherlands
}

Second, Fumis and Deheinzelin state that European ICU physicians are, in comparison with their North American colleagues, less inclined to withdraw treatment. This statement is not in concordance with our own experience. The withdrawal rate in our Dutch ICU is $83 \%$ of the patients who died in the ICU [3]. This result is fully supported by the ETHICUS (Ethics in European Intensive Care Units) study, which reported that withdrawal of treatment is a generally accepted form of endof-life care in Europe, especially in Northern Europe [4].

Finally, in our opinion, it is the treating physician who, after consultation with colleagues, has the knowledge and experience to make a clear and fair judgment concerning the prognosis of a patient. In case of a poor prognosis, it is the duty of that physician to make the withdrawal decision clear and acceptable to the patient, the relatives, and the nurses. to acknowledge the high indices observed in the study by Epker and colleagues.

Family members of ICU patients are at higher risk of anxiety, depression, and PTSR $[2,6]$. But we must point out that family members frequently surmise a wrong prognosis regarding the patient [7] and that satisfaction with the intensive care treatment is related to doctors' behavior in the sharing of information and decision making [8], factors that may contribute to PTSR [2]. As such, we believe that there is room for improvement in the shared decision process and that the clinical team must help surrogates to better understand the medical issues [5].

Finally, given the willingness of staff and families to participate in the end-of-life process disclosed in our study, it is premature to assume that only the treating physician and colleagues should make such a decision 
and then make such a decision clear and acceptable. Probably only a very difficult-to-design randomized study could properly answer such a question.

\section{Abbreviations}

ICU, intensive care unit; PTSR, post-traumatic stress reaction.

\section{Competing interests}

The authors declare that they have no competing interests.

\section{Published: 2 March 2011}

\section{References}

1. Fumis RR, Deheinzelin D: Respiratory support withdrawal in intensive care units: families, physicians and nurses views on two hypothetical clinical scenarios. Crit Care 2010, 14:R235.

2. Azoulay E, Pochard F, Kentish-Barnes N, Chevret S, Aboab J, Adrie C, Annane D, Bleichner G, Bollaert PE, Darmon M, Fassier T, Galliot R, Garrouste-Orgeas M, Goulenok C, Goldgran-Toledano D, Hayon J, Jourdain M, Kaidomar M, Laplace C, Larché J, Liotier J, Papazian L, Poisson C, Reignier J, Saidi F, Schlemmer B; FAMIREA Study Group: Risk of post-traumatic stress symptoms in family members of intensive care unit patients. Am J Respir Crit Care Med 2005, 171:987-994.

3. Epker JL, Bakker J, Kompanje EJ: The use of opioids and sedatives and time until death after withdrawing mechanical ventilation and vasoactive drugs in a Dutch intensive care unit. Anesth Analg 2011 Feb 8. [Epub ahead of print].

4. Sprung CL, Cohen SL, Sjokvist P, Baras M, Bulow HH, Hovilehto S, Ledoux D, Lippert A, Maia P, Phelan D, Schobersberger W, Wennberg E, Woodcock T;

Ethicus Study Group: End-of-life practices in European intensive care units: the Ethicus Study. JAMA 2003, 290:790-797.

5. Carlet J, Thijs LG, Antonelli M, Cassell J, Cox P, Hill N, Hinds C, Pimentel JM, Reinhart K, Thompson BT: Challenges in end-of-life care in the ICU. Statement of the 5 th International Consensus Conference in Critical Care: Brussels, Belgium, April 2003. Intensive Care Med 2004, 30:770-784.

6. Fumis RR, Deheinzelin D: Family members of critically ill cancer patients: assessing the symptoms of anxiety and depression. Intensive Care Med 2009, 35:899-902.

7. Fumis RR, Nishimoto IN, Deheinzelin D: Measuring satisfaction in family members of critically ill cancer patients in Brazil. Intensive Care Med 2006 32:124-128.

8. Fumis RR, Nishimoto IN, Deheinzelin D: Families' interactions with physicians in the intensive care unit: the impact on family's satisfaction. J Crit Care 2008, 23:281-286.

doi:10.1186/cc10033

Cite this article as: Epker $\mathrm{J}$, et al:: Respiratory support withdrawal in intensive care units: international differences stressed and straightened! Critical Care 2011, 15:405 